\title{
Characterization of Lightning Observed by Multiple High-Speed Cameras
}

\author{
L. Antunes, A. C. V. Saraiva, O Pinto Jr., J. Alves, L. Z. S. Campos, E. S. A. M. Luz, C. Medeiros, T. S. Buzato. \\ ELAT, Atmospheric Electricity Group. \\ INPE, National Institute for Space Research. \\ São José dos Campos, SP, BRAZIL. \\ E-mail: antunesla86@gmail.com.
}

\begin{abstract}
This study aims to analyze the visible parameters of the cloud-to-ground discharges such as the average multiplicity, continuing current duration and interstroke interval. Several authors already analyzed these parameters for groups of thunderstorms in some regions. Although some authors did not find differences between those characteristics between different regions, there has not been a comprehensive amount of lightning recordings from the same thunderstorm, in order to evaluate such parameters in a storm-to-storm basis. The lightning data for this work was obtained by four high-speed cameras (Phantom v9.1) set to record 2500 frames per second. They were located in São José dos Campos, Brazil, as part of the project RAMMER (Automated Multi-Camera Network for Monitoring and Study of Lightning Flashes). Five thunderstorm days were selected for this study and some of the data were recorded manually, which provided a higher number of confirmed cloud-to-ground lightning records. A total of 357 flashes were recorded. As far as the authors know, this is the first time that four high-speed cameras are looking to the same thunderstorm from different locations. Because of the number of cameras and their positions, the coverage area is larger, thereby increasing the number of flashes recorded from the same thunderstorm. These samples allow a more representative analysis of the lightning parameters mentioned above.
\end{abstract}

Keywords-lightning; high-speed cameras; thunderstorm days; continuing current; multiplicity; interstroke interval.

\section{INTRODUCTION}

Some of the main characteristics of negative cloud-toground (CG) lightning flashes are the number of stroke per flash (multiplicity), the interstroke interval, the duration of the flash and continuing current, as well as the number of ground contacts. Studies of these characteristics have already been made by different authors. Reference [1] correlated the electric field and records high-speed camera to analyze some of the characteristics of 193 flashes that occurred in three different thunderstorms in New Mexico. Reference [2] studied some properties of 76 negative CG lightning flashes registered with electric field and films on TV camera in Florida. Reference [3] reported electric field measurements of 137 flashes during 2 thunderstorms in Sweden; Reference [4] reported a study of the characteristics of 81 flashes for two thunderstorms in Sri-
Lanka recorded with electric field antenna. Reference [5], through the comparison between the U. S. National Lightning Detection Network (NLDN), electric field and optical observations, made an analysis of the multiplicity of $\mathrm{CG}$ flashes in Florida and New Mexico. Reference [6] conducted a study of 233 negative CG lightning flashes obtained during 27 thunderstorms recorded in Brazil with high-speed cameras and correlated with RINDAT (Integrated Network of National Lightning Detection) network data. Reference [7] analyzed the characteristics of lightning produced by thunderstorms in two different climate regimes using the same instrumentation. The parameters were obtained through recordings of high-speed cameras and data from lightning localization systems (LLS). A total of 432 negative CG lighting were observed in several thunderstorms.

It is very important to know the characteristics of cloud-toground lightning flashes, because some may affect human activity directly. In [5] it is shown, for example, the importance of knowing the ratio between the single and multiple flashes for protection of transmission lines.

The use of high-speed cameras for recording lightning images provides high temporal resolution optical information and this enables the discrimination of return strokes even when the interstroke interval is very small. This technique has been used since the mid 1990's [8], [9].

The high-speed camera has become one of the main tools to study the visible characteristics of lightning flashes; however, every technique has its limitations. Given the electronic construction of this type of camera, it cannot record at the same time it transfers the files to the PC. Thus, the time between filming depends on the number of recorded frames and their spatial resolution, which influences the total file size of each individual video. As a consequence, individual highspeed cameras tend to observe only a relatively small sample of the total content of lightning from the thunderstorms. Thus, the use of only one high-speed camera does not make possible the creation of a significant daily database of lightning records. In order to achieve this objective the project RAMMER (Portuguese acronym for Multi-camera 
Automatized Network for Lightning Monitoring and Studies [10]) was created. RAMMER is a network of high-speed cameras whose objective is the observation of thunderstorms at various angles, automatically triggered, increasing the total number of recorded flashes per thunderstorm.

The observations in this study were made during the summer of 2012/2013 in the city of São José dos Campos and surroundings. The RAMMER network had four sensors strategically placed to cover the area of interest. Five days of thunderstorm that had the largest number of flashes recorded were chosen.

The objective of this work is to analyze the characteristics of lightning individually for each thunderstorm day, since the number of cameras observing the same region allowed the acquisition of a significant database. It will be also checked whether there are relevant differences between some lightning characteristics per day. The results should improve understanding of the determining factors in formation of lightning on one given region.

\section{INSTRUMENTATION}

The high-speed cameras used in this work are part of the project RAMMER [11]. Currently the network is formed by four observation stations, three of which are fixed and one mobile.

Each of the fixed stations was mounted in a standard way and contains the same equipment: a) a Phantom V9.1 highspeed camera set to operate with a spatial resolution of $1200 \mathrm{x}$ 500 pixels at 2500 frames per second; b) a personal computer with 2 TB of hard disk space, responsible for running system control and data storage software; c) a GPS antenna to synchronize each frame recorded with a precision of $1 \mathrm{~ns}$, allowing the correlation between the lightning data recorded by the camera with the information provided by LLS; and d) a photodiode sensor that emits a triggering pulse when drastic changes in ambient light occurs. This pulse activates the camera at the exact moment of the return stroke, allowing the automatic operation of the sensors. Housing has been designed to protect the equipment of climate action, allowing each station to operate outdoors. The RAMMER Mobile Station was manually operated and did not require both housing and automatic triggering system.

The position of each station was carefully chosen so that all cameras observe the central region of the city of São José dos Campos. Their names were given according to the order of installation. The first one installed was RAMMER 1 (R1), fixed on the basis of a telecommunication tower of Vanguarda TV channel at São José dos Campos. The second, RAMMER 2 (R2), was installed in a tower of Simoldes Plasticos, located in Caçapava, a neighbor city to São José dos Campos. RAMMER 3 (R3) was placed in the tower of Advanced Studies Institute of Aeronautics (IEAv) in São José dos Campos. Finally, the fourth station, RAMMER Mobile (RM), was adapted in a car and operated within the campus of the University of Vale do Paraíba (UNIVAP).
From the three stations programmed to work automatically, only R1 did it full time, while R2 and R3 were operated manually during the thunderstorm days chosen for this work. All recordings occurred in the summer of $2012 / 2013$, and only those days with the highest number of flashes recorded, 18, 19 and 22 February 2013, and 06 and 08 March 2013, where chosen. There were 700 videos recorded during this period. Videos with lightning outside the field of view were discarded from the sample, as well as, intra-cloud discharges and positive flashes (the polarity was given by the LLS). After the data reduction, 357 videos containing confirmed negatives $\mathrm{CG}$ flashes were used for the analysis.

The LLS used in this work were BrasilDAT (Brazilian Lightning Detection Network) [12] and RINDAT (Integrated Network of National Lightning Detection) [13]. The LLS data were used in this work to identify the location and polarity of the return strokes.

Table I shows the amount of daily recorded negative CG flashes for each thunderstorm and by each RAMMER station. The flashes that have been filmed by more than one camera were counted only once.

TABLE I. NUMBER OF RECORDED LIGHTNING FLASHES PER THUNDERSTORM DAY BY THE RAMMER NETWORK.

\begin{tabular}{|c|c|c|c|c|c|}
\hline Day & R1 & R2 & R3 & RM & Subtotal \\
\hline $\mathbf{0 2} / \mathbf{1 8}$ & $0 *$ & 25 & 23 & 19 & 67 \\
\hline $\mathbf{0 2} / \mathbf{1 9}$ & 11 & 17 & 19 & 27 & 74 \\
\hline $\mathbf{0 2} / \mathbf{2 2}$ & 6 & 14 & 13 & 22 & 55 \\
\hline $\mathbf{0 3} / \mathbf{0 6}$ & 14 & 31 & 33 & 38 & 116 \\
\hline $\mathbf{0 3} / \mathbf{0 8}$ & 18 & 8 & 1 & 18 & 45 \\
\hline & & & & Total & 357 \\
\hline
\end{tabular}

\section{ANALYSES AND RESULTS}

The lightning data will be analyzed for each thunderstorm day, and also all together in order to ascertain whether there are significant differences between days. A total of 357 negative CG flash were selected for analysis, of which $26 \%$ (93 flashes) were not identified as negative or positive polarity by the LLS. Due to the presence of high multiplicity and visible branching, characteristics that are prevalent in negative CG flashes [14], these flashes were classified as negative. The visible characteristics to be analyzed are flash multiplicity and duration, interstroke time interval, duration of long continuing current (CC) (greater than $40 \mathrm{~ms}$ ) ([15] and [1]), duration of short continuing current (CC) (between 10 and $40 \mathrm{~ms}$ ) [16], and number of ground contact points.

\section{A. Multiplicity}

The total number of lightning return strokes recorded for all days was 1493, grouped into 357 flashes, which 
corresponds to an aritmetic mean of 4.2 strokes per flash. $24.3 \%$ (87) of all flashes were composed by only one return stroke. These values are similar to the results found by [6] in São José dos Campos (Brazil).

\section{TABLE II. OBSERVATION TIMES, NUMBER OF RECORDED FLASHES PER DAY, PERCENTAGE OF FLASHES DETECTED BY THE LLS, PERCENTAGE OF SINGLE STROKE FLASHES AND AVERAGE MULTIPLICITY FOR EACH} THUNDERSTORM DAY.

\begin{tabular}{|c|c|c|c|c|c|}
\hline Day & $\begin{array}{l}\text { Observation } \\
\text { period (min) }\end{array}$ & $\begin{array}{l}\text { Recorded } \\
\text { flashes }\end{array}$ & $\begin{array}{l}\text { \% of LLS } \\
\text { matches }\end{array}$ & $\begin{array}{l}\text { of single- } \\
\text { stroke flashes }\end{array}$ & $\begin{array}{l}\text { Average } \\
\text { Multiplicity }\end{array}$ \\
\hline $\mathbf{0 2 / 1 8}$ & 140 & 285 & 81.0 & 16.4 & 4.4 \\
\hline $\mathbf{0 2 / 1 9}$ & 141 & 332 & 74.3 & 23.0 & 4.5 \\
\hline $\mathbf{0 2 / 2 2}$ & 133 & 143 & 70.9 & 45.5 & 2.6 \\
\hline $\mathbf{0 3} / \mathbf{0 6}$ & 209 & 574 & 79.3 & 15.5 & 5.0 \\
\hline $\mathbf{0 3} / \mathbf{0 8}$ & 126 & 155 & 48.9 & 34.8 & 3.4 \\
\hline All & 749 & 1489 & 73.1 & 24.3 & 4.2 \\
\hline
\end{tabular}

Table II shows the total duration of the observation periods of each thunderstorm, the recorded flash count, the percentage of flashes detected by BrasilDAT, the percentage of single stroke flashes, the arithmetic mean of the multiplicity (individually per thunderstorm), and the total multiplicity of the entire dataset. It is possible to notice a significant variation between thunderstorm days, the number of single flashes and the arithmetic mean of multiplicity, remembering that the region where all thunderstorms occurred is the same. On day 22 we observed the greatest variation, with $45.45 \%$ of single stroke flashes, which lowered the mean of multiplicity to 2.6, a value much lower than those found in the literature. ([6] and [7]). Between the day with lowest multiplicity and the day with the highest, a factor of two was found.

Figure 1 presents the compiled distribution of the multiplicity for all observed flashes and its shape is similar to what is usually found in literature. The distributions of flash multiplicities also presented differences, as shown in Figure 2.

The highest multiplicity, 18, was observed on February $18^{\text {th }}$, when $25.4 \%$ (17) of the flashes had multiplicities greater than 5 .

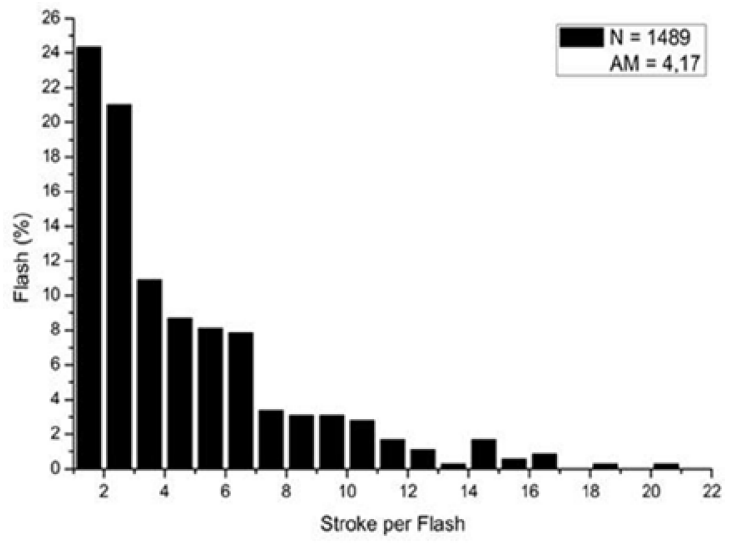

Fig. 1. Distribution of the number of stroke per flash (multiplicity) for the entire dataset.
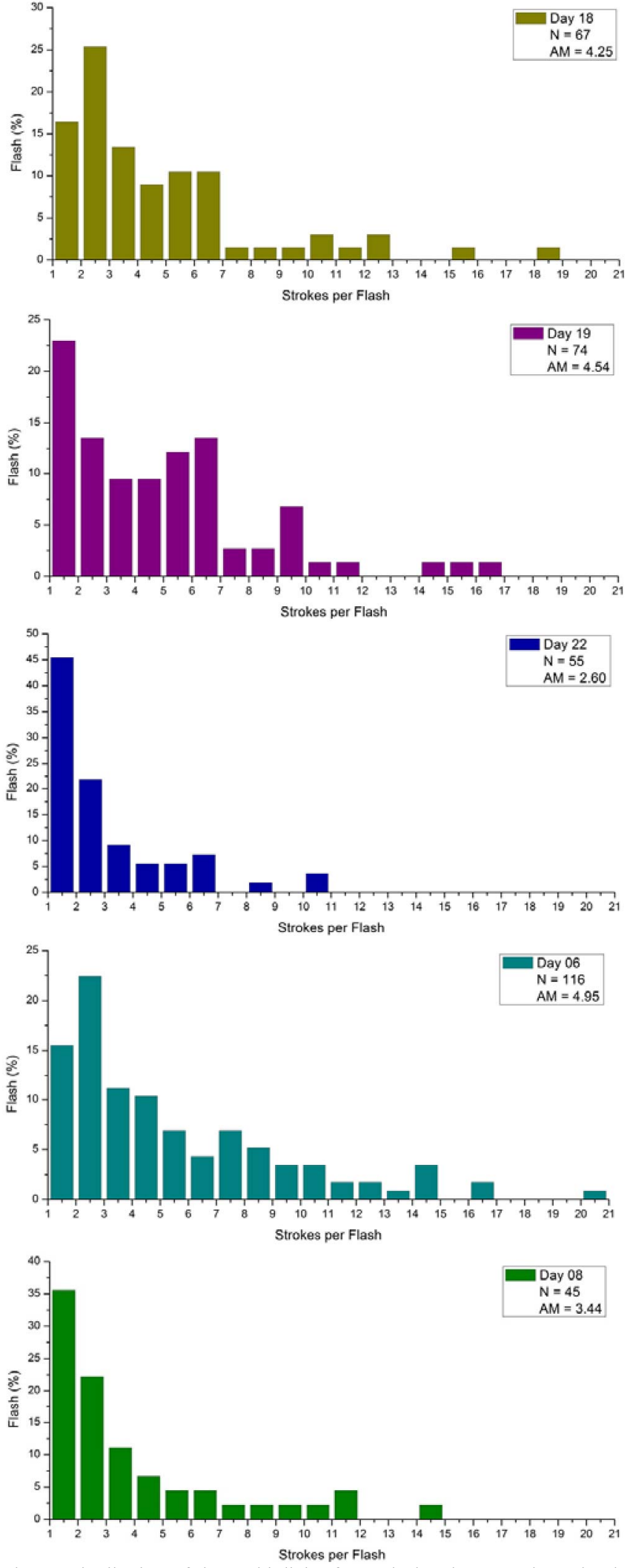

Fig. 2. Distribution of the multiplicity for each thunderstorm day. The day identification, sample size and aritmetic means are marked on each figure.

On February $19^{\text {th }}$ the largest multiplicity was 16 and $32.4 \%$ (24) of the flashes presented multiplicities greater than 5. 
February $22^{\text {nd }}$ had the higher multiplicity of only 10 and $12.7 \%$ (7) of flashes with multiplicities greater than 5. On March $6^{\text {th }}$, the highest multiplicity of the whole dataset was found (20) with $33.6 \%$ (39) of the flashes with more than 5 strokes. In March $8^{\text {th }}$, the highest multiplicity was 14 , with $20 \%$ (9) of the flashes presenting more than 5 discharges.

\section{B. Flash Duration}

The duration of the flash was defined as the time interval between the moment that the first return stroke touches the ground and the end of the faintest luminosity of the last subsequent stroke or the end of its continuing current (if present). 270 flashes were used for this analysis because the duration of single stroke flashes (87) was not included. The geometric mean (GM) of the overall durations was $332.8 \mathrm{~ms}$. This value is higher than those obtained for the same region in previous studies [6],[7].

The longest duration was found on February $19^{\text {th }}$ with $1875 \mathrm{~ms}$, corresponding to a flash of multiplicity 18 . This value is the highest recorded in the literature so far. Table III shows the geometric mean of the flash durations, as well as the maximum and minimum durations found in each thunderstorm.

Figure 3 shows the general distribution of all flash durations. Figure 4 presents the distributions per thunderstorm day. Again, February $22^{\text {nd }}$ had the most different distribution of the whole set. The average duration of the day was 219.8 $\mathrm{ms}$ while the general average calculated was $332.8 \mathrm{~ms}$.

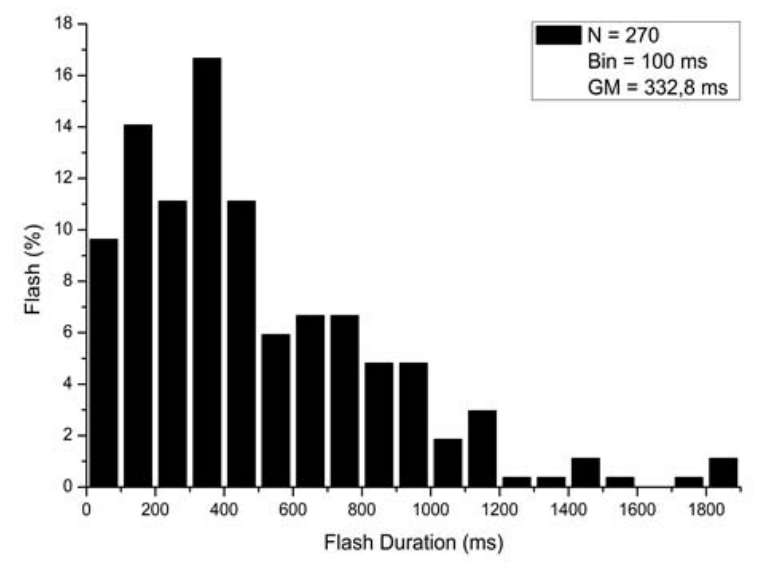

Fig. 3. Distribution of flash duration of 270 flashes. The single stroke events (87) were not included in the analysis.

\section{Interstroke Interval}

The 357 analyzed flashes produced 1332 interstroke intervals. The very short intervals (of the order of $0.4 \mathrm{~ms}$ ) were associated with forked strokes, i. e., strokes that hit the ground at the same time. Table IV shows the number of forked strokes per day which, although small, had a relatively large range (from 2 to 9). These strokes were classified as forked because two or more ground contact points were observed hitting the ground within 390 us time scale (exposure time of the camera).
TABLE III. MAXIMUM, MINIMUM AND GEOMETRIC MEAN OF FLASH DURATIONS.

\begin{tabular}{|c|c|c|c|}
\hline Day & $\begin{array}{c}\text { Minimum duration } \\
(\mathbf{m s})\end{array}$ & $\begin{array}{c}\text { Maximum } \\
\text { Duration }(\mathbf{m s})\end{array}$ & $\begin{array}{c}\text { Geometric Mean } \\
(\mathbf{m s})\end{array}$ \\
\hline $\mathbf{0 2} / \mathbf{1 8}$ & 0.8 & 1875 & 275.5 \\
\hline $\mathbf{0 2} / \mathbf{1 9}$ & 72.8 & 1867 & 473.1 \\
\hline $\mathbf{0 2} / \mathbf{2 2}$ & 2.8 & 852 & 219.8 \\
\hline $\mathbf{0 3} / \mathbf{0 6}$ & 0.4 & 1800 & 324.7 \\
\hline $\mathbf{0 3} / \mathbf{0 8}$ & 35 & 1495.6 & 400.6 \\
\hline Total & 0.4 & 1875 & 332.8 \\
\hline
\end{tabular}

The longest intervals were associated with long continuing current. Intervals longer than 1 second were discarded since they were probably related to a different flash. None of these longer intervals corresponded to sequences of strokes following the same channel to the ground, which is evidence that these events are not the same flash. The longer interval considered was $772 \mathrm{~ms}$ on March $6^{\text {th }}$, between the first and second return stroke, that followed the same path to the ground, presenting a long continuing current of $162 \mathrm{~ms}$. The overall GM was $52.7 \mathrm{~ms}$, a value similar to the values found in other studies, around $60 \mathrm{~ms}[5,6,7$,

Table IV shows the sample size and the GM of the interstroke intervals for each day, and the number of forked strokes. The lowest GM was on March $6^{\text {th }}$, which also had the highest multiplicity (4.9) and greatest number of flashes recorded (116). The day with the lowest average interstroke intervals was also the one that had the lowest multiplicity (2.6), on February $22^{\text {nd }}$.

TABLE IV. GEOMETRIC MEAN OF THE INTERSTROKE INTERVALS, NUMBER OF FORKED STROKES AND SAMPLE SIZE FOR EACH THUNDERSTORM DAY

\begin{tabular}{|c|c|c|c|}
\hline Day & $\begin{array}{c}\text { Forked } \\
\text { strokes } \\
\text { (number) }\end{array}$ & $\begin{array}{c}\text { Interstroke } \\
\text { intervals } \\
\text { (number) }\end{array}$ & $\begin{array}{c}\text { Interstroke } \\
\text { intervals } \\
\text { GM (ms) }\end{array}$ \\
\hline $\mathbf{0 2 / 1 8}$ & 4 & 213 & 55.0 \\
\hline $\mathbf{0 2 / 1 9}$ & 9 & 257 & 58.8 \\
\hline $\mathbf{0 2 / 2 2}$ & 3 & 86 & 60.2 \\
\hline $\mathbf{0 3 / 0 6}$ & 6 & 461 & 48.1 \\
\hline $\mathbf{0 3 / 0 8}$ & 2 & 115 & 49.5 \\
\hline Total & 22 & 1332 & 52.7 \\
\hline
\end{tabular}

Figure 5 shows the distribution of interstroke intervals for all flashes. Figure 6 is a composed graph of the interstroke intervals for each day; it was displayed in that form since no significant differences were found among the thunderstorm days.

\section{Continuing current}

The continuing current (CC) can be defined by a constant variation of the electric field, reflected as a continuing duration of the channel luminosity after the return stroke process and can be classified into two major groups depending on their duration $[1,15,16]$. The $\mathrm{CC}$ is considered long when the duration exceeds $40 \mathrm{~ms}[1,15]$ and short when its duration is between 10 and $40 \mathrm{~ms}$ [16]. 

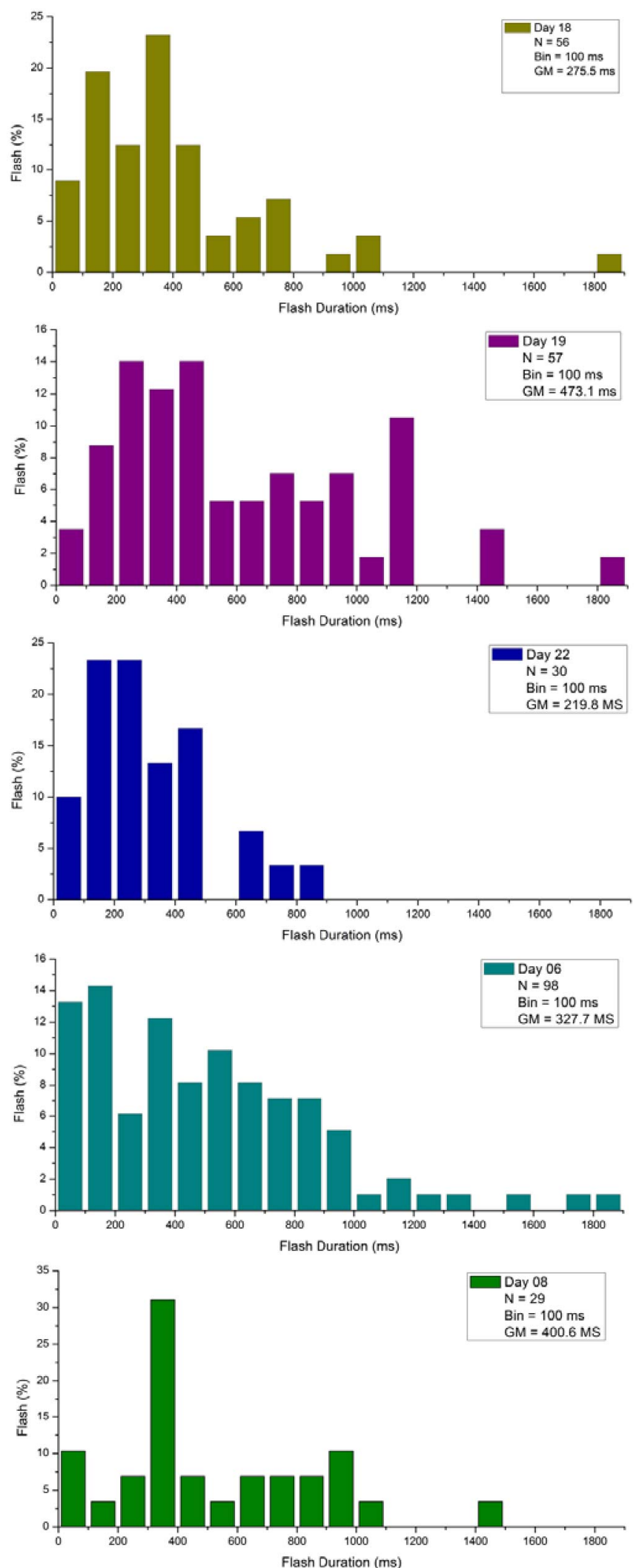

Fig. 4: Distribution of flash durations for each thunderstorm day. Identification of day, bin size, sample size and geometric means are marked on each figure.

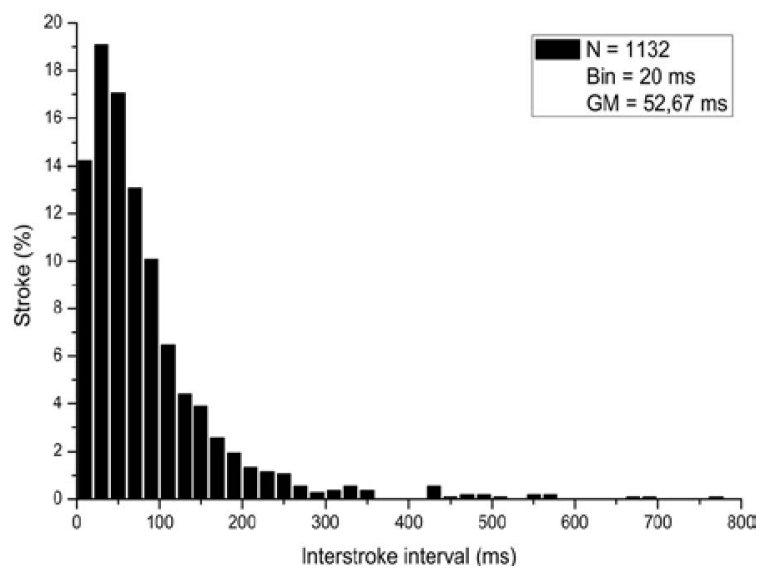

Fig 5. Distribution of interstroke intervals for the combined dataset. 1132 intervals were used in this plot.

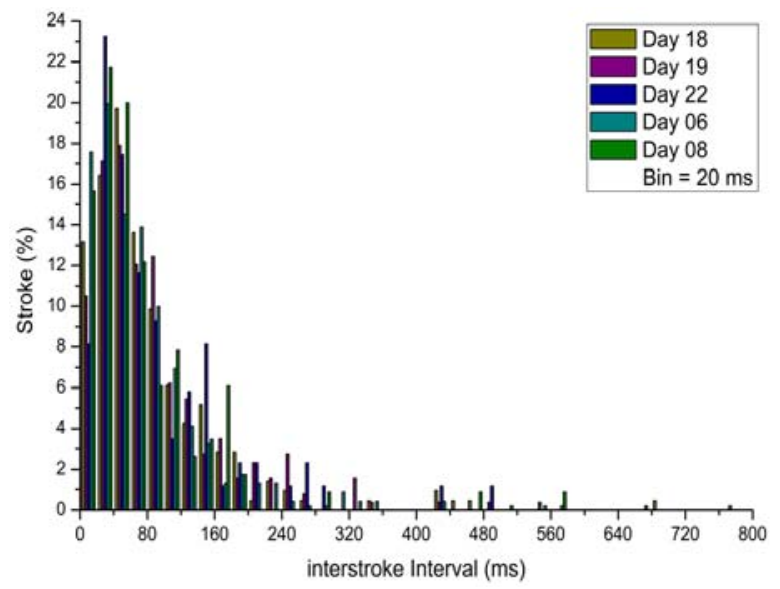

Fig 6. Distribution of interstroke intervals for each thunderstorm day. It is important to notice that all the individual distributions are very similar to the combined dataset

In this study, $\mathrm{CC}$ was defined through video recordings of high-speed cameras. However, these measurements could be underestimated because of the distance between the return stroke and the camera, or when the channel is obscured, for example, due to the presence of intervening rain.

Tables V and VI show the incidence of long and short CC, respectively, for each thunderstorm day. The largest $\mathrm{CC}$ found was $753.7 \mathrm{~ms}$ on February $19^{\text {th }}$, on the fifth and last return stroke of a lightning flash that had four different contact points to the ground.

TABLE V. STATISTICS OF SHORT CONTINUING CURRENT (CC) DURATION PER DAY.

\begin{tabular}{|c|c|c|c|}
\hline Day & $\begin{array}{c}\text { \# of flashes } \\
\text { with short CC }\end{array}$ & $\begin{array}{c}\text { \% of flashes } \\
\text { with short CC }\end{array}$ & $\begin{array}{c}\text { GM of short } \\
\text { CC durations } \\
(\mathbf{m s})\end{array}$ \\
\hline $\mathbf{0 2 / 1 8}$ & 7 & 10.4 & 16.6 \\
\hline $\mathbf{0 2} / \mathbf{1 9}$ & 22 & 29.7 & 16.3 \\
\hline $\mathbf{0 2} / \mathbf{2 2}$ & 13 & 23.6 & 16.3 \\
\hline $\mathbf{0 3} / \mathbf{0 6}$ & 19 & 16.4 & 16.3 \\
\hline $\mathbf{0 3} / \mathbf{0 8}$ & 4 & 8.9 & 15.0 \\
\hline All & 65 & 18.2 & 16.3 \\
\hline
\end{tabular}


TABLE VI. STATISTICS OF LONG CONTINUING CURRENT (CC) DURATION PER DAY.

\begin{tabular}{|c|c|c|c|}
\hline Day & $\begin{array}{c}\text { \# of flashes } \\
\text { with long CC }\end{array}$ & $\begin{array}{c}\text { \%o of flashes } \\
\text { with long CC }\end{array}$ & $\begin{array}{c}\text { GM of long CC } \\
\text { durations (ms) }\end{array}$ \\
\hline $\mathbf{0 2 / 1 8}$ & 9 & 13.4 & 98.2 \\
\hline $\mathbf{0 2} / \mathbf{1 9}$ & 22 & 29.7 & 111.8 \\
\hline $\mathbf{0 2} / \mathbf{2 2}$ & 16 & 29.0 & 120.7 \\
\hline $\mathbf{0 3 / 0 6}$ & 20 & 17.2 & 128.2 \\
\hline $\mathbf{0 3 / 0 8}$ & 14 & 31.1 & 182.8 \\
\hline All & 81 & 22.7 & 123.5 \\
\hline
\end{tabular}

Figures 7 and 8 show the distribution of long and short CC durations, respectively, for the whole dataset. The percentage of flashes with long CC was $22.6 \%$ (81), while $18.2 \%$ (65) of the flashes that presented short CC. Therefore, $40.8 \%$ of the flashes showed some kind of continuing current.

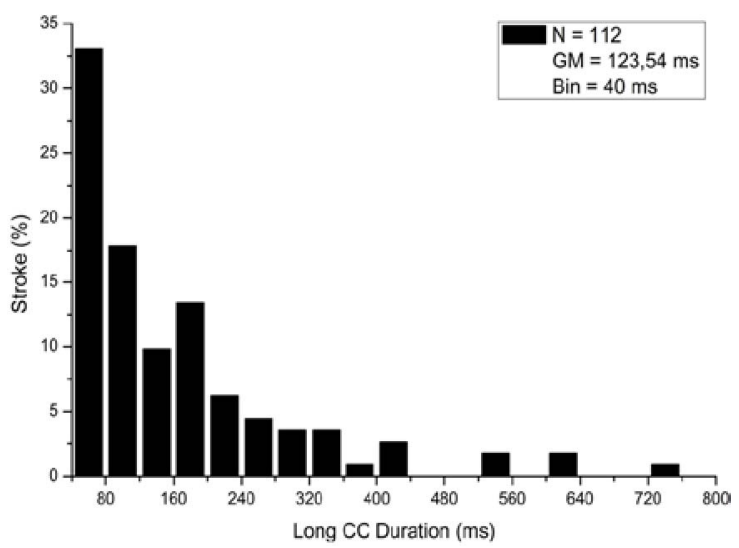

Fig. 7. Distribution of long continuing current (CC) duration for the whole dataset. 112 strokes presented long CC.

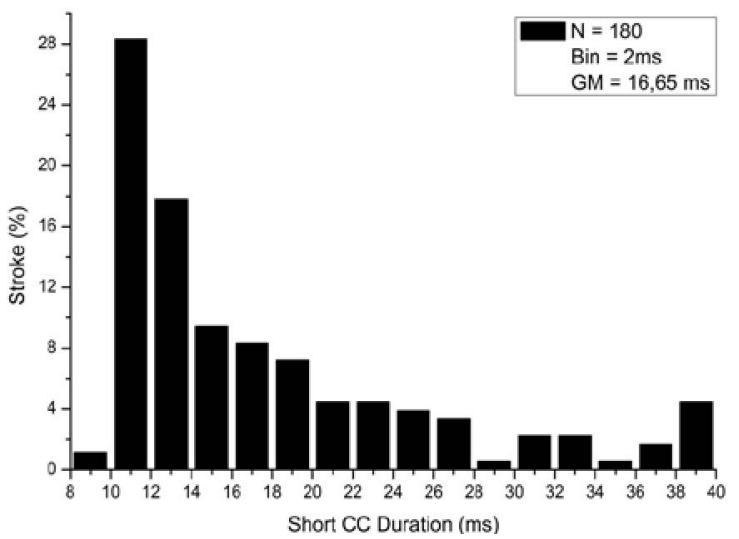

Fig. 8. Distribution of short continuing current (CC) durations for the whole dataset. 180 strokes presented long CC.

The distribution of long and short CC had no significant variations from one day to another, so Figures 9 and 10 show the composite distributions of long and short CC durations for all five thunderstorm days.

\section{E. Number of Ground Contacts}

Table VII shows how many flashes produced a certain number of ground contact points, on each day. The GM for all flashes was 1.45 and the geometric mean for multiple flashes (excluding single stroke flashes) was 1.63. Nearly half $(41.5 \%)$ of the flashes observed presented more than one point of contact on the ground. Excluding the single stroke flashes from the total, the percentage increases to $54.5 \%$ (147) of flashes with multiple ground contact points (Table VIII).

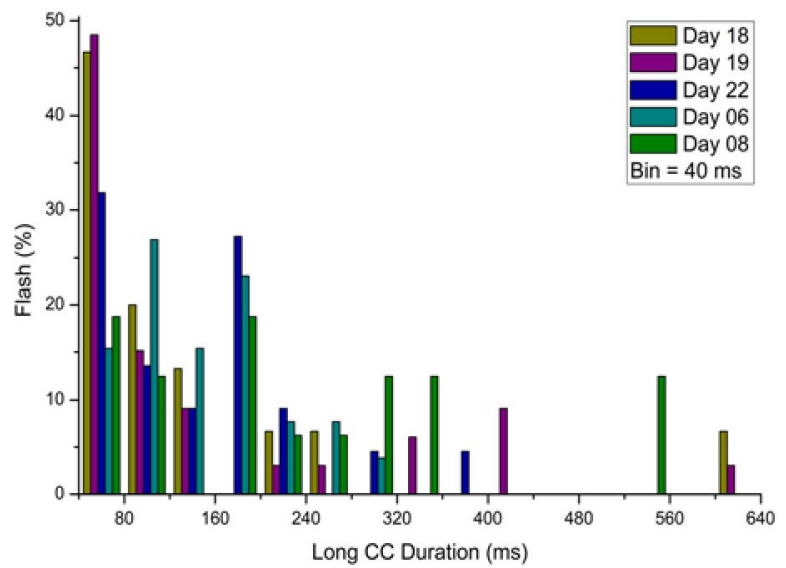

Fig. 9. Composed distribution of long $\mathrm{CC}$ durations from the 5 thunderstorm days.

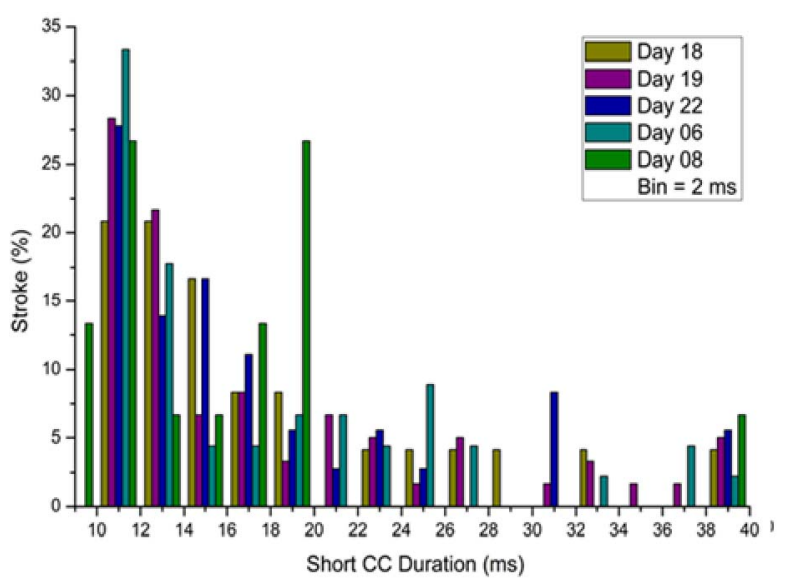

Fig 10. Composed distribution of short $\mathrm{CC}$ durations from the 5 thunderstorm days.

The figure 10 shows the distribution of the number of contact points for the entire dataset. The number of multiple flashes with more than three contact points was 23 , or $8.5 \%$, higher than previous statistics made for the same region [7]. Figure 11 shows the distribution of contact points for each thunderstorm day.

TABLE VII. NUMBER OF FLASHES WITH MULTIPLE GROUND CONTACTS, PERCENTAGES AND ARITHMETIC MEAN.

\begin{tabular}{|c|c|c|c|}
\hline Day & $\begin{array}{c}\text { Number of } \\
\text { flashes of } \\
\text { multiple } \\
\text { ground } \\
\text { contacts }\end{array}$ & $\begin{array}{c}\text { Percentage } \\
\text { of multiple } \\
\text { points of } \\
\text { contacts. } \\
\mathbf{( \% )}\end{array}$ & $\begin{array}{c}\text { Arithmetic } \\
\text { Mean of } \\
\text { multiple } \\
\text { ground } \\
\text { contacts }\end{array}$ \\
\hline $\mathbf{0 2 / 1 8}$ & 36 & 53,7 & 1,96 \\
\hline $\mathbf{0 2 / 1 9}$ & 29 & 39,2 & 2.03 \\
\hline $\mathbf{0 2 / 2 2}$ & 16 & 29,1 & 1.80 \\
\hline $\mathbf{0 3 / 0 6}$ & 50 & 43,1 & 1.76 \\
\hline $\mathbf{0 3 / 0 8}$ & 16 & 35,5 & 1.82 \\
\hline $\mathbf{A l l}$ & 147 & 41,17 & 1.87 \\
\hline
\end{tabular}


TABLE VIII. NUMBER OF POINTS OF CONTACT WITH THE GROUND FOR EACH THUNDERSTORM DAY AND TOTAL.

\begin{tabular}{|c|c|c|c|c|c|c|}
\cline { 2 - 6 } \multicolumn{1}{c|}{} & \multicolumn{4}{c|}{ Number of ground contact points } & \multicolumn{1}{c|}{} \\
\hline Day & Two & Three & Four & Five & Six & Total \\
\hline $\mathbf{0 2 / 1 8}$ & 23 & 9 & 3 & 1 & 0 & 36 \\
\hline $\mathbf{0 2 / 1 9}$ & 14 & 7 & 4 & 1 & 3 & 29 \\
\hline $\mathbf{0 2 / 2 2}$ & 12 & 1 & 2 & 1 & 0 & 16 \\
\hline $\mathbf{0 3 / 0 6}$ & 34 & 10 & 4 & 1 & 1 & 50 \\
\hline $\mathbf{0 3 / 0 8}$ & 11 & 3 & 1 & 1 & 0 & 16 \\
\hline All & 94 & 30 & 14 & 5 & 4 & 147 \\
\hline
\end{tabular}

\section{DISCUSSIONS}

The amount of flashes recorded during the 2012/2013 campaign with the RAMMER network allowed a statistical study of negative lightning flashes per day. The number of flashes recorded each day varied appreciably. While on March $6^{\text {th }} 116$ flashes were recorded, on February $8^{\text {th }}$ this number was only 45. Although the present study does not deal with differences of lightning flashes per thunderstorm type, differences were found in some lightning characteristics per thunderstorm day. This indicates that the daily synoptic condition plays an important role in the formation lightning flashes. A rough analysis on the thunderstorm characteristics was performed and there was no indication of relation between days with more or less lightning flashes associated and the thunderstorm type. A future work will address this comparison properly.

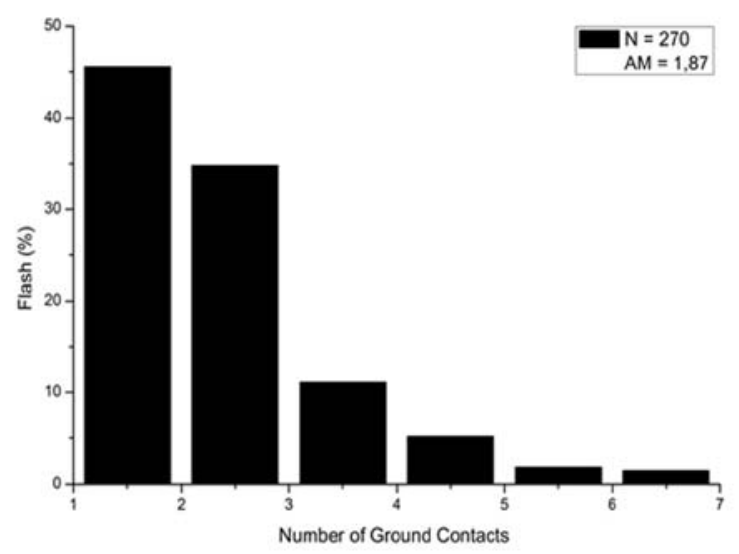

Fig. 10. Distribution of ground contact points for the entire dataset.

The first parameter analyzed was flash multiplicity. In [6] and [7], the arithmetic mean of multiplicity found for the same region was 3.9. In this work, the arithmetic mean for all flashes was 4.17. These numbers are very similar, however, the analysis showed considerable variation per day. On March $6^{\text {th }}$, for example, the average multiplicity was 4.95 with $40.5 \%$ (47) presenting multiplicities greater than 5, while on February $22^{\text {nd }}$ the average was 2.6 and only $18.2 \%$ (10) presented multiplicities greater than 5 .
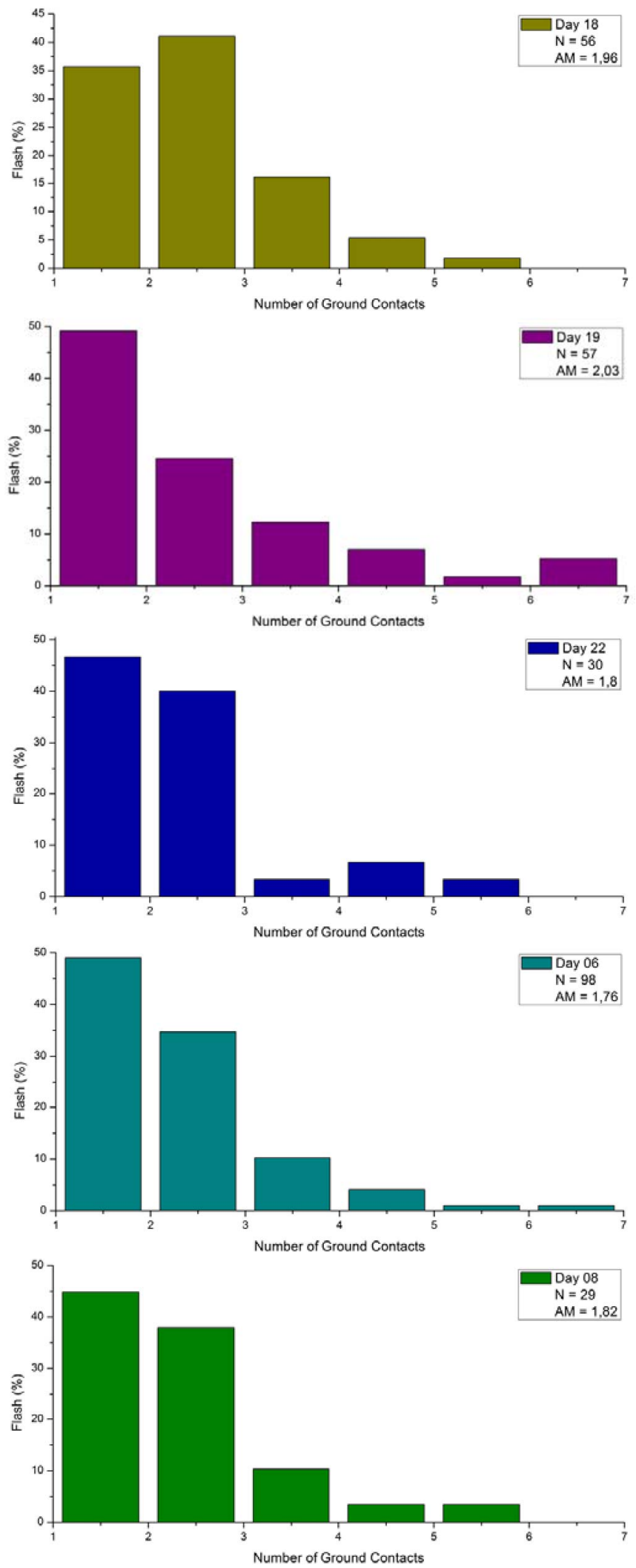

Fig 11. Distribution of the number of ground contact points for each day

It is interesting to notice that March $06^{\text {th }}$ also showed the lowest percentage of single stroke flashes (15.5\%), while 
February $22^{\text {nd }}$ had the highest percentage of single stroke flashes $(45.5 \%)$. This value is almost twice the mean value found for single flashes $(24.3 \%)$ for all thunderstorm days. Correlating the last two columns of Table II, one can verify that average multiplicity is linearly correlated with the occurrence of single stroke flashes.

The geometric mean for all flash durations was $332.8 \mathrm{~ms}$, higher than $229 \mathrm{~ms}$, the value already found for the same region by [7]. The daily geometric mean also presented variations. The lowest geometric mean of flash durations occurred on the February $22^{\text {nd }}(219.8 \mathrm{~ms})$, and almost twice that value was observed on March $08^{\text {th }}(400.5 \mathrm{~ms})$. The flash which showed longer duration occurred on the day February $18^{\text {th }}$, lasting about $1875 \mathrm{~ms}$. This is the highest value recorded in the literature to date. On February $22^{\text {nd }}$, the maximum duration found for a flash was $816 \mathrm{~ms}$, which is much lower than the values found in the other days.

Interestingly, February $22^{\text {nd }}$ had the lowest number of subsequent strokes (138) and the highest mean value for the interstroke interval with the geometric mean around $60 \mathrm{~ms}$. In contrast, March $06^{\text {th }}$ had the highest number of subsequent strokes (574) and the lowest geometric mean of the interstroke intervals with $48.1 \mathrm{~ms}$.

The geometric mean of long CC for all flashes was 123.5 ms and greater CC was found on February $19^{\text {th }}$ with approximately $753.7 \mathrm{~ms}$, corresponding to a flash with multiplicity 6 and 4 multiple ground contact points.

Considering all the thunderstorm days, 8.5\% (23) of flashes produced more than three distinct contact points on the ground. This value is higher than $2.6 \%$, which was previously found for the same region [7]. Considering only the 57 flashes of February $19^{\text {th }}$, this percentage increases to $14 \%(8)$.

\section{CONCLUSIONS}

In order to verify if there are variations on some visible characteristics of negative cloud-to-ground lightning flashes per thunderstorm day, it was made an observation campaign during the summer of 2012/2013 in São José dos Campos. There were four high-speed cameras observing the same region, so that it was possible to record a significant number of flashes in each day. Even on March $8^{\text {th }}$, the quantity of flashes recorded was 45 , which is sufficient for a statistical analysis. The measurements of lightning characteristics per thunderstorm day are presented for the first time.

When the analysis was done by adding all flashes, the values found are similar to those found in other studies that examined the same parameters. ([14], [4], [3], [2], [6], [7]).When the analysis was made by thunderstorm day, some values found were distinct, like the multiplicity that varied between 2.6 and 4.95, or the amount of single stroke flashes. However, the two quantities seem to be closely related, as showed in Table II.

The presented results showed that February $22^{\text {nd }}$ is a very interesting case study. The lower flash durations and average multiplicity indicate that either the thunderstorm from where they were recorded or the synoptic conditions of the day did not allow the occurrence of long lasting flashes and consequently higher multiplicities. The higher average interstroke intervals for this day still need to be evaluated, but it is the same found by other works that recorded flashes in the same region. This day will be studied in more details in a future work.

In the next stage of this work, the database will be divided according to the types of storm with the intention of checking whether there are still significant differences in the characteristics of the strokes. For this purpose, the camera data shall be used as auxiliary tools of weather radar data and satellite images in order to search explanations for these differences.

\section{ACKNOWLEDGMENT}

The authors would like to thanks Vanguarda TV channel, Simoldes Plásticos and Instituto de Estudos Avançados (IEAv) for their support during the 2012/2013 observation campaign. A. C. V. Saraiva would like to thanks FAPESP under grant number 2010/01742-2 for the support during the RAMMER campaign. O. Pinto Jr. also thanks FAPESP for grant number 08/56711-4.

\section{REFERENCES}

[1] Kitagawa, N., M. Brook, and E. J. Workman (1962), Continuingcurrentsin cloud-to-ground lightning discharges, J. Geophys. Res., $67,637-647$.

[2] Rakov, V. A., M. A. Uman, and R. Thottappillil (1994), Review of lightning properties from electric field and TVobservations, J. Geophys. Res., $99,10,745-10,750$.

[3] Cooray, V., and H. Perez (1994), Some features of lightning flashes observed in Sweden, J. Geophys. Res., 99, 10,683-10,688.

[4] Cooray, V., and K. P. S. Jayaratne (1994), Characteristics of lightning flashes observed in Sri Lanka in the tropics, J. Geophys. Res., 99, 21,05121,056 .

[5] Rakov, V. A., and G. R. Huffines (2003), Return stroke multiplicity of negative cloud to ground lightning flashes, J. Appl. Meteorol., 42

[6] Saba, M. M. F.; Bellarotti, M. G.; Pinto Jr, O. (2006), Negative cloudto-ground lightning properties from high-speed video observations. J. Geophys. Res., v.111, p. D03101.

[7] Saraiva, A. C. V.; Saba, M. M. F.; Pinto Jr. O.; Cummins, K. L.; Krider, E. P.; Campos, L. Z. S. (2010).A comparative study of negative cloud[8] Mazur, V., P. R. Krehbiel, and X.-M. Shao (1995), Correlated highspeed video and interferometric observations of a cloud-to-ground flash, J. Geophys. Res., 100, 25,731-25,753.

[9] Mazur, V., X.-M. Shao, and P. R. Krehbiel (1998), Spider lightning in intracloud and positive cloud-to-ground flashes, J. Geophys. Res., 103, $19,811-19,822$.

[10] Saraiva, A. C. V., O. Pinto Jr., M. C. A. Ferreira, G. S. Zepka, M. M. F. Saba (2011), RAMMER Network Observations During Summer 2011/2012, paper presented at the XIV International Conf. on Atm. Electricity, Rio de Janeiro, Brazil.

[11] Saraiva, A. C. V., Pinto Jr. O.; Zepka G. S.;(2012), RAMMER network observations during summer 2011/2012, paper presented at the International Lightning Detection Conference (ILDC), and International Lightning Metheorology Conference (ILMC), Vaisala, Broomfield-Colorado ,EUA.

[12] Naccarato, K. P, (2012), Lightning detection in Southeastern Brazil from the new Brazilian Total Lightning Network (BrasilDAT), paper presented at the International Conference on Lightning Protection (ICLP), Vienna, Austria. 
[13] Naccarato, K. P. (2006), Análise das características dos relâmpagos no sudeste do Brasil. INPE-14083-TDI/1069J.

[14] Rakov, V. A., and M. A. Uman (2003), Lightning: Physics and Effects, Cambridge Univ. Press, Cambridge, U. K
[15] Brook, M., N. Kitagawa, and E. J. Workman (1962), Quantitative study of strokes and continuing currents in lightning discharges to ground, J. Geophys. Res., 67, 649-659.

[16] Shindo, T., and M. A. Uman (1989), Continuing current in negative cloudto- ground lightning, J. Geophys. Res., 94, 5189- 5198. 